\title{
The Thermal Behavior of Hybrid Fabric Reinforced Composites with Stratified Filled Epoxy Matrix
}

\begin{abstract}
VICTORITA STEFANESCU, ANA BOBOC, ADRIAN COJ AN, RADU BOSOANCA, CRISTIAN MUNTENITA, MARINA BUNEA*
Dunarea de J os University of Galati, Research and Development Centre for Thermoset Matrix Composites, 111 Domneasca Str., 800008, Galati, Romania

In this research, the thermal performance of the hybrid composites with modified epoxy matrix was investigated. The results were compared with those presented by the hybrid composites with homogeneous epoxy matrix. For understand the effects of the replacement of lower specific density glass fabric by higher specific density glass fabric, the thermal properties of the hybrid epoxy composites were determined by comparison to the thermal results of composites reinforced with lower specific density glass fabric with those of the hybrid epoxy materials reinforced with higher specific density glass fabric. Also, the effects on the specific heat and thermal expansion coefficient of the used fabric types in outer sheets of the composites were studied.
\end{abstract}

Keywords: coefficient of thermal expansion; specific heat, hybrid composites, filled matrix

The composite materials are being used in many domains, where they are subjects of large ranges of temperature variation; in this regard it is very important to study their thermal behavior. The large differences of temperatures may affect the structural stability of composites [1-3]. For thermal investigation, usually, three parameters are analyzed: the coefficient of thermal expansion, the specific heat and the coefficient of thermal conductivity of materials. As any composite, for polymer matrix ones, the thermal properties are influenced both by the nature and properties of polymer and nature and properties of reinforcement or additives or fillers. The thermoset resins are used for obtaining of polymeric composites with high thermal performance, due their higher thermal stability in comparison with thermoplastic polymers [4].

The occurrence of dimensional variation due to heat stress is undesirable, because the too high heat stress may leads to the deformations and the unstick of laminate layers, resulting the decrease of mechanical performance $[5,6]$, that is why it is recommended to reinforce the polymer composites with plain weave fabrics due its high structural stability [7-10]. Often, fabrics made of glass fibers, carbon fibers, and aramid fibers (or combinations of these types of fibers) are used as reinforcements due to their mechanical properties and their fire resistance but also because of their special thermal properties $[4,11,12]$. Regarding the thermal conductivity of fibers, the glass and aramid fibers exhibit low thermal conductivity and the carbon fibers are good thermally conducting. In dependence of destination of reinforced polymer composites, hybrid composites can be formed with advantageous combinations of each fiber constituent [13] and showing special properties of multi-functional advanced materials.

Also, aiming to improve the mechanical and thermal properties of laminates, during the preparation of polymer matrix fillers, like starch, clay, CNT, carbon black, aramid powder etc. might be used. In this case it has to be taken into account the fact that the composite properties depend on matrix-fiber interface and the presence of fillers leads to appearance of discontinuities [14]. So, reducing the fillers dimensions and increasing of their concentration, the mechanical and thermal properties may be improved. The investigation of thermal behavior of starch/epoxy and clay/epoxy composites in ref. [15] showed that the thermal properties depend more on fillers concentration than on fillers nature.

This study concerns with the investigation effects generates by two types of glass fibers fabrics, placed on the outer layers of laminate materials and the effect of fillers used during the preparation of polymer matrix over the thermal behavior of 16 different hybrid composite laminates each one containing 17 reinforcement layers. The purpose of this study was to improve the mechanical, thermal and electrical properties of fabric reinforced epoxy composites. This paper contains only the thermal analysis (excepting the coefficient of thermal conductivity) of hybrid laminate composites.

\section{Experimental part}

Materials and methods

The bonds between layers being very important, the hybrid laminates were formed by the lay-up method which provides high quality samples with minimum defects [16]. For this study the modified epoxy resin was used as stratified matrix and various fabrics as reinforcement in order to obtain hybrid stratified materials with different properties at different layers.

For this research 16 different hybrid laminates were formed each one made of 17 layers of reinforcement. So, the medial layer was made of a hybrid type of fabric. This fabric is a modified mixed fabric made of aramid and carbon fiber tows in geometry $1 \times 2$ in warp direction and $2 \times 1$ in fill direction. Each second aramid fiber tow of the fill direction was replaced with a glass fiber tow together with a $0.2 \mathrm{~mm}$ diameter tin covered cooper wire, such as the final fabric is of simple type but with three alternating kinds of tows on the fill. This type of fabric was denoted by $M$ [17]. All the other used fabrics $\left(173 \mathrm{~g} / \mathrm{m}^{2}\right.$ aramid fibers fabric - K, $160 \mathrm{~g} / \mathrm{m}^{2}$ carbon fibers fabric - C, $163 \mathrm{~g} / \mathrm{m}^{2}$ glass fibers fabric $-1 \mathrm{G}$ and $390 \mathrm{~g} / \mathrm{m}^{2}$ glass fibers fabric-2G) are also plain type. The matrix of all hybrid materials is made of epoxy resin (EPIPHEN RE 4020-DE 4020 system). The

* email: marina.bunea@ugal.ro 
hybrid composites denoted by $\mathrm{H}$ were formed with homogeneous epoxy matrix and the hybrid composites denoted by $F$ were formed with stratified filled epoxy matrix. The stratified filled epoxy matrix was formed by modifying the epoxy system with two fillers combination types: MF1 - $10 \%$ wr of potato starch, $10 \%$ wr of aramid powder and $10 \%$ wr of carbon black; MF2-10\% wr of potato starch, $10 \%$ wr of carbon black and, $10 \%$ wr of barium ferrite (weight ratios being determined relative to the amount of polymer). As itcan noticed in table 1 for the hybrid materials the reinforcement layers are numbered from 1 to 17 (with number 9 being made of above mentioned special type of fabric) and related to that, in the case of modified epoxy matrix materials the 1 - 5 and 13 - 17 layers were imbued

\begin{tabular}{|c|c|}
\hline Material & Layer configuration \\
\hline $\mathrm{N} 11 \mathrm{H}, \mathrm{N} 11 \mathrm{~F}$ & {$\left[\begin{array}{c}\frac{0_{3 \mathrm{C}}}{0_{3 \mathrm{~K}}} \\
\frac{0_{21 \mathrm{G}}}{\overline{90_{\mathrm{M}}}}\end{array}\right]_{\varsigma}$} \\
\hline $\mathrm{N} 12 \mathrm{H}, \mathrm{N} 12 \mathrm{~F}$ & 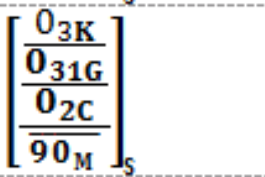 \\
\hline $\mathrm{N} 13 \mathrm{H}, \mathrm{N} 13 \mathrm{~F}$ & {$\left[\begin{array}{l}\frac{0_{31 G}}{0_{3 C}} \\
\frac{0_{2 K}}{\overline{90}}\end{array}\right]$} \\
\hline $\mathrm{N} 14 \mathrm{H}, \mathrm{N} 14 \mathrm{~F}$ & {$\left[\begin{array}{l}\frac{0_{31 G}}{0_{3 K}} \\
\frac{0_{2 C}}{\overline{90}}\end{array}\right]$} \\
\hline $\mathrm{N} 21 \mathrm{H}, \mathrm{N} 21 \mathrm{~F}$ & {$\left[\frac{\frac{0_{3 C}}{0_{3 K}}}{\overline{0_{22 G}}} \overline{\overline{90_{M}}}\right]_{S}$} \\
\hline $\mathrm{N} 22 \mathrm{H}, \mathrm{N} 22 \mathrm{~F}$ & 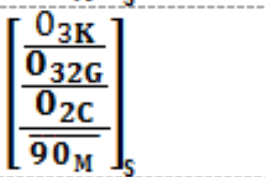 \\
\hline $\mathrm{N} 23 \mathrm{H}, \mathrm{N} 23 \mathrm{~F}$ & {$\left[\begin{array}{l}\frac{0_{32 \mathrm{G}}}{0_{3 \mathrm{C}}} \\
\frac{0_{2 \mathrm{~K}}}{\overline{90_{M}}}\end{array}\right]$} \\
\hline $\mathrm{N} 24 \mathrm{H}, \mathrm{N} 24 \mathrm{~F}$ & {$\left[\begin{array}{l}\frac{0_{32 \mathrm{G}}}{0_{3 \mathrm{~K}}} \\
\frac{0_{2 \mathrm{C}}}{\overline{90_{M}}}\end{array}\right]_{S}$} \\
\hline
\end{tabular}

Table 1 LAYER CONFIGURATION OF HYBRID LAMINATES with MF1 filled epoxy matrix and, for the 6- 12 layers were imbued with MF2 filled epoxy matrix prior to be placed into the mold. Table 1 contains also the denomination of each material.

The coefficient of thermal expansion was measured using TMA SDTA 840 instrument (fig. 1.a.) with a heating rate of $20^{\circ} \mathrm{C} / \mathrm{min}$ from 30 to $200^{\circ} \mathrm{C}$. The specific heat was measured using DSC 1 instrument (fig. 1.b.) by heating from 30 to $330^{\circ} \mathrm{C}$ and by cooling from 330 to $30^{\circ} \mathrm{C}$ with a heating, respective, cooling ratio of $20^{\circ} \mathrm{C} / \mathrm{min}$.

\section{Results and discussions}

The thermal analysis was made on the limits of the linear behavior of the two parameters that had been investigated (coefficient of linear expansion and specific heat) for the composites. So, the values of coefficient of thermal linear expansion were calculated for $40-60^{\circ} \mathrm{C}$ interval and for 110 $170^{\circ} \mathrm{C}$ interval of temperatures (fig. 2, fig. 3 and fig. 4). The hybrid reinforced epoxy composites with outer layers made of carbon fabric showed the lowest values of linear

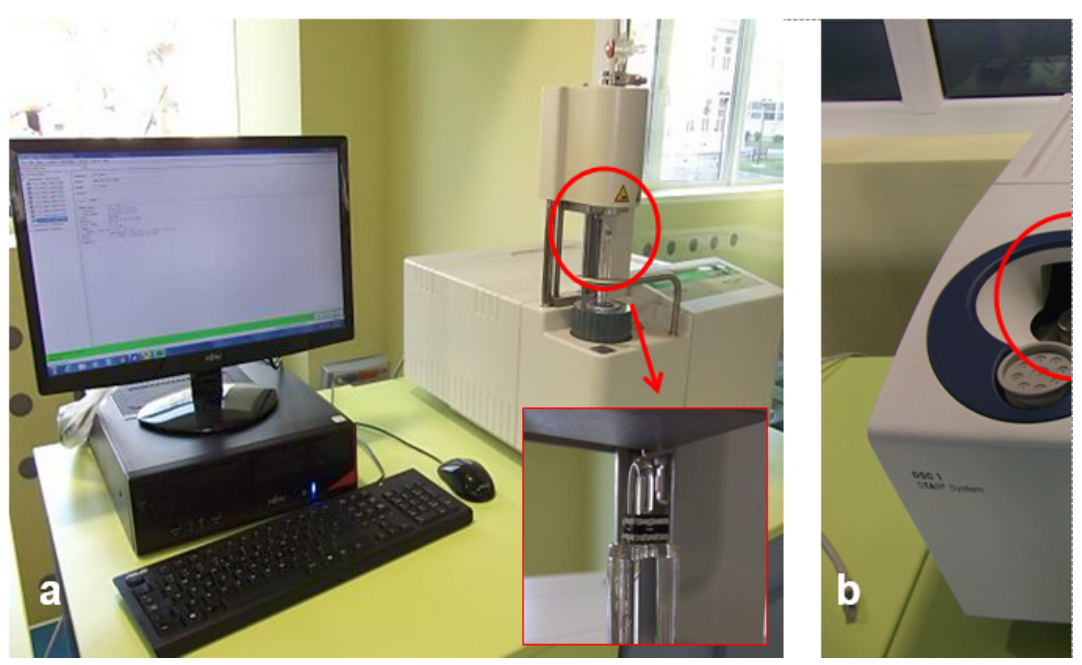

Fig. 1. The experimental methods of thermal measurements: $a$ - the measurements of coefficient of thermal expansion with TMA SDTA 840 instrument; $b$ - the measurements of specific heat with DSC 1 instrument.

Fig. 2. Typical profile curve for materials thickness vs temperature during TMA analysis

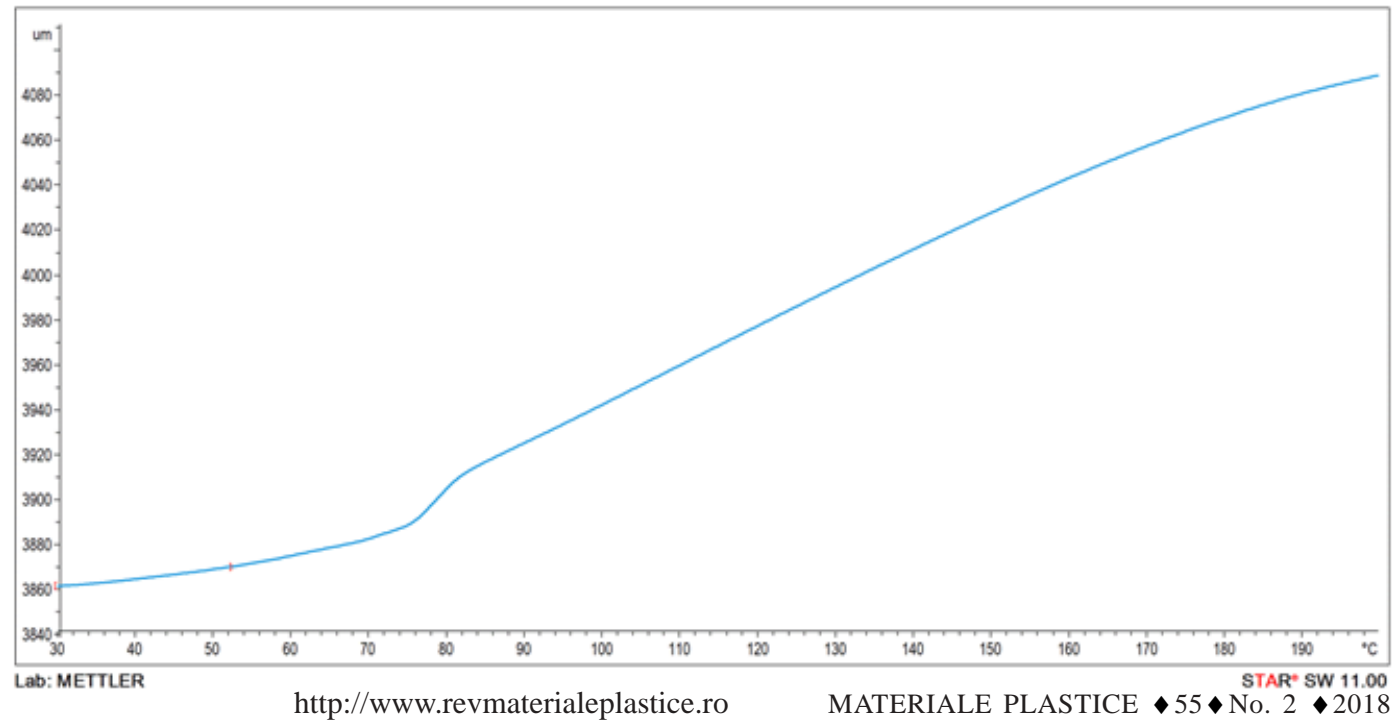


Expansion coefficient of composites with homogeneous epoxy matrix

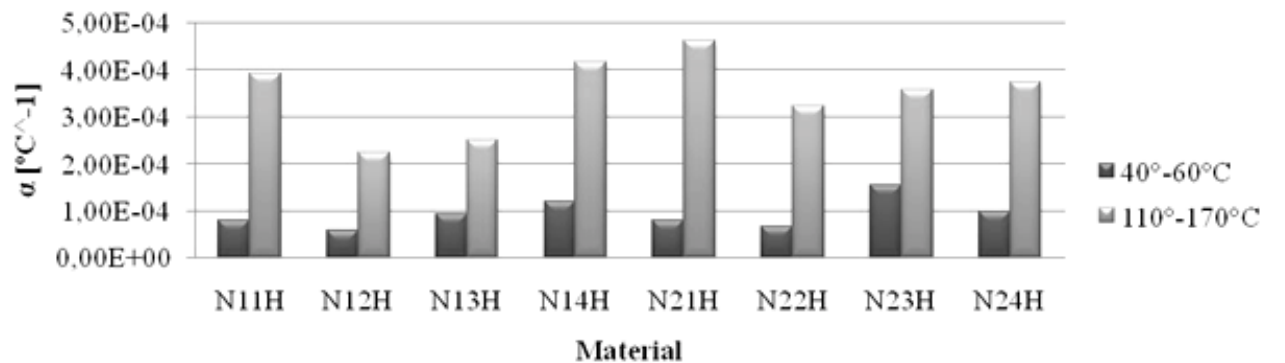

Fig. 3. Coefficient of thermal expansion for hybrid composites with homogeneous epoxy matrix

Material

Expansion coefficient of composites with heterogeneous epoxy matrix
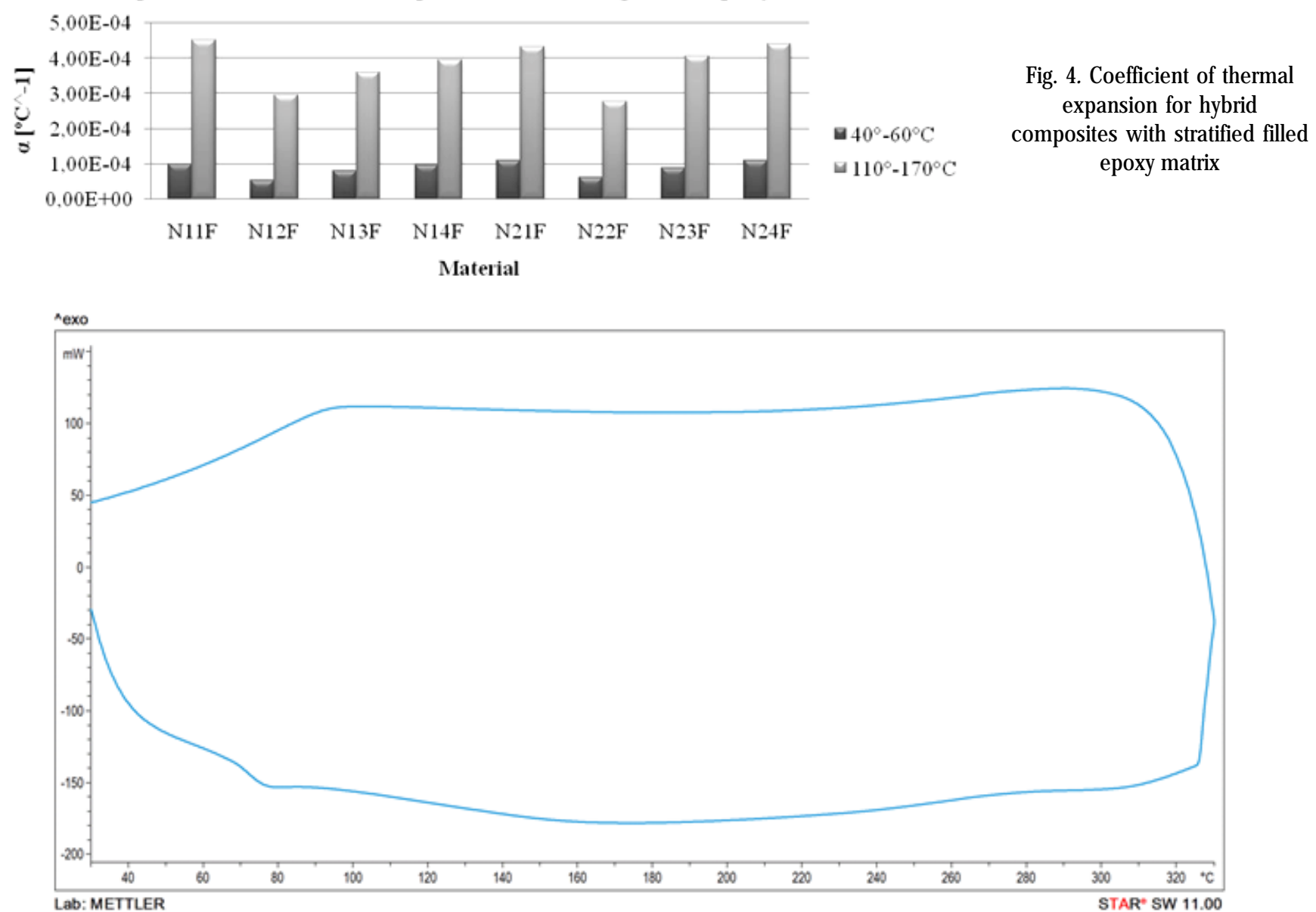

Fig. 5. Typical profile curve for heat flow vs temperature during DSC analysis

expansion coefficient on both temperature ranges. The values of expansion coefficient determined on $40-60^{\circ} \mathrm{C}$ interval increases in order: $\mathrm{N} 12 \mathrm{H}<\mathrm{N} 11 \mathrm{H}<\mathrm{N} 13 \mathrm{H}<\mathrm{N} 14 \mathrm{H}$ for composites reinforced with glass fabric with lower specific density and $\mathrm{N} 22 \mathrm{H}<\mathrm{N} 21 \mathrm{H}<\mathrm{N} 24 \mathrm{H}<\mathrm{N} 23 \mathrm{H}$ for composites reinforced with glass fabric with higher specific density, how it can be seen in figure 3. Making a comparison between the expansion coefficient values of hybrid composites with non-filled epoxy matrix on this temperature ranges, it was observed that by increasing of specific density of glass fiber fabric, the expansion coefficient values were decreased for hybrid composites with outer layers made of carbon fabric and middle layers made of glass fabric and for hybrid composites with outer layers made of glass fabric and middle layers made of carbon fabric. For the other materials, the results showed an increasing of the expansion coefficient values. By modifying of epoxy matrix, it was determined that by increasing of glass fabric specific density the values of coefficient of thermal linear expansion also increased. The order of increasing of coefficient of thermal linear expansion values of composites was changed as follows: $\mathrm{N} 12 \mathrm{~F}<\mathrm{N} 13 \mathrm{~F}<\mathrm{N} 14 \mathrm{~F}<\mathrm{N} 11 \mathrm{~F}$ for composites reinforced with glass fabric with lower specific density and $\mathrm{N} 22 \mathrm{~F}<\mathrm{N} 23 \mathrm{~F}<\mathrm{N} 21 \mathrm{~F}<\mathrm{N} 24 \mathrm{~F}$ for composites reinforced with glass fabric with higher specific density, how it can be seen in fig. 4. Also, by modifying of epoxy matrix, it was observed an increasing of expansion coefficient of composites with carbon outer layers and of composite with $2 \mathrm{G}$ glass outer layers and carbon middle layers.

On $110-170^{\circ} \mathrm{C}$ temperature interval, it was observed a decreasing of expansion coefficient value by the replacement of higher specific density glass fabric with one having lower specific density, with the exception of hybrid epoxy composite with of glass outer layers and carbon in the middle layers (fig. 3). On this temperature range, the expansion coefficient values increase in order $\mathrm{N} 12 \mathrm{H}<\mathrm{N} 13 \mathrm{H}<\mathrm{N} 11 \mathrm{H}<\mathrm{N} 14 \mathrm{H}$ for hybrid composites reinforced with lower specific density glass fabric and $\mathrm{N} 22 \mathrm{H}<\mathrm{N} 23 \mathrm{H}<\mathrm{N} 24 \mathrm{H}<\mathrm{N} 21 \mathrm{H}$ for hybrid composites reinforced with higher specific density glass fabric. In case of hybrid epoxy composites with stratified filled matrix, it 
was observed an increasing of thermal expansion coefficient by increasing of glass fabric specific density for hybrid materials with glass outer layers and inversely for the other materials (fig. 4). By modifying epoxy matrix, the recorded values showed a change in order of expansion coefficient increasing of materials such as N14F $<\mathrm{N11F}$ and $\mathrm{N} 21 \mathrm{~F}<\mathrm{N} 24 \mathrm{~F}$. The modification of epoxy matrix of hybrid composites reinforced with lower specific density glass fabric lead to an increase of thermal expansion coefficient on $110-170^{\circ} \mathrm{C}$ temperature range, excepting the composite made of glass outer layers and carbon middle layers. In case of reinforced materials with higher specific density glass fabric, the modification of epoxy matrix lead to a decrease of expansion coefficient for composites with carbon and aramid outer layers.

The values of specific heat were calculated by average of both linear curves values (heating and cooling curves fig. 5) on 45-70, 80-200 and $200-300^{\circ} \mathrm{C}$ temperature ranges (fig. 6 to fig. 9). Analyzing the heating and cooling curves, it can be determined the effects on specific heat of glass fabric specific density, outer layers fabric and fillers. How it can be remarked in figure 6 , on all temperatures ranges of heating and cooling curves, the specific heat show the same order of values increasing in case of hybrid epoxy composites reinforced with lower specific density glass fabric: $\mathrm{N} 11 \mathrm{H}<\mathrm{N} 14 \mathrm{H}<\mathrm{N} 12 \mathrm{H}<\mathrm{N} 13 \mathrm{H}$. But regarding the hybrid epoxy composites reinforced with higher specific density glass fabric the order of increasing of specific heat is the same on $45-70^{\circ} \mathrm{C}$ and $80-200^{\circ} \mathrm{C}$ temperature ranges of heating curves $\mathrm{N} 22 \mathrm{H}<\mathrm{N} 21 \mathrm{H}<\mathrm{N} 24 \mathrm{H}<\mathrm{N} 23 \mathrm{H}$. On $200-$ $300^{\circ} \mathrm{C}$ temperature range of heating curves and on all temperature ranges of cooling curves the composites made of glass outer layers change their order (figs. 6 and 8). In fig. 6 and figure 7, it can be observed that on 80-200 and $200-300^{\circ} \mathrm{C}$ temperature ranges of heat curves, the thermal behavior of hybrid composites made of glass outer layers and aramid middle layers is different from other materials. Because in the transition from $80-200^{\circ} \mathrm{C}$ range to $200-300^{\circ} \mathrm{C}$ range the specific heat of these composites exhibit a decreasing of values comparing with the other materials, whose specific heat values increase. Which means that these materials keep their different thermal behavior, also, on cooling temperature ranges.

On heating $45-705^{\circ} \mathrm{C}$ temperature range, it can be noticed that by increasing of glass fabric specific density, the specific heat of hybrid epoxy composites is also increasing, excepting the specific heat of composite with glass outer layers and aramid middle layers, which is decreasing (fig. 6.). But on cooling temperature range the hybrid composite with aramid middle layers and, especially, the hybrid composite with aramid outer layers exhibited a decreasing of specific heat with increasing of glass fabric specific density (fig. 8). So, how it can be seen in figure 9 , the specific heat of composites can be improved by modifying of epoxy matrix with fillers, which led to increasing of specific heat by decreasing of glass fabric specific density. But, also, the specific heat of composite with glass outer layers and carbon middle layers increased. The hybrid composites with stratified filled epoxy matrix on cooling temperature range showed the same specific

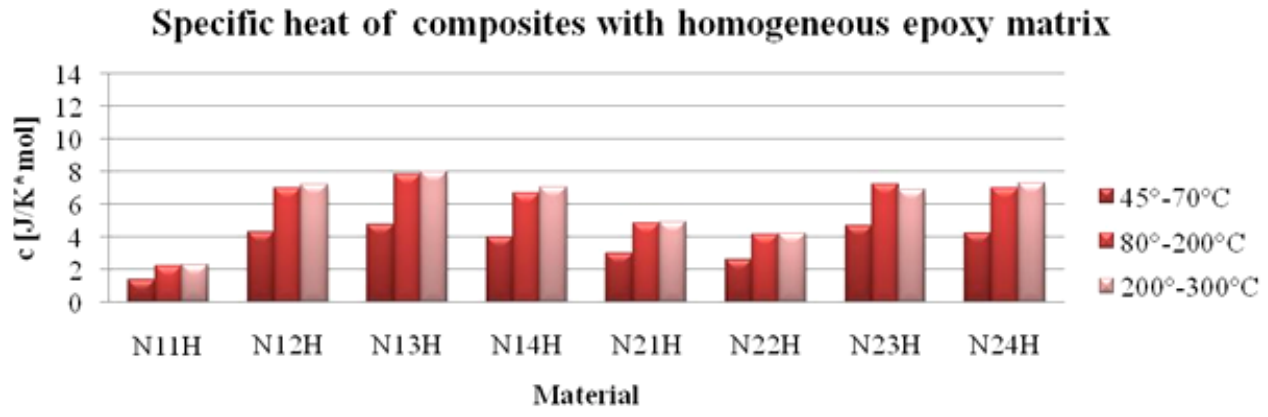

Fig. 6. Specific heat of hybrid composites with homogeneous epoxy matrix measured on heating curves.

Material

Specific heat of composites with heterogeneous epoxy matrix

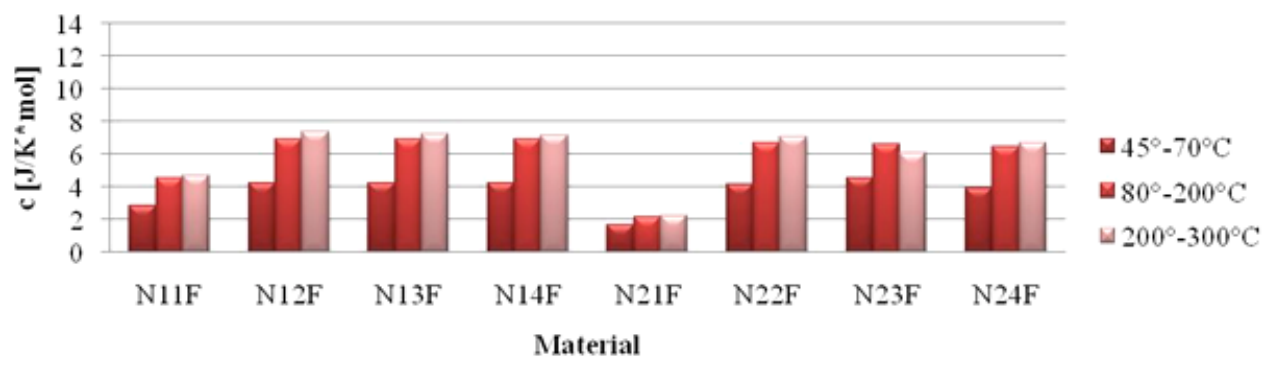

Fig. 7. Specific heat of hybrid composites with stratified filled epoxy matrix measured on heating curves.

Specific heat of composites with homogeneous epoxy matrix

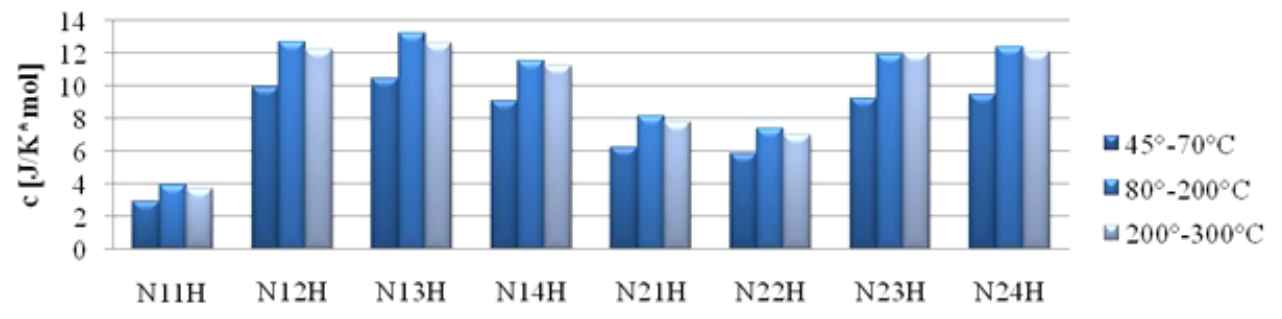

Fig. 8. Specific heat of hybrid composites with homogeneous epoxy matrix measured on cooling curves.

Material 
Specific heat of composites with heterogeneous epoxy matrix

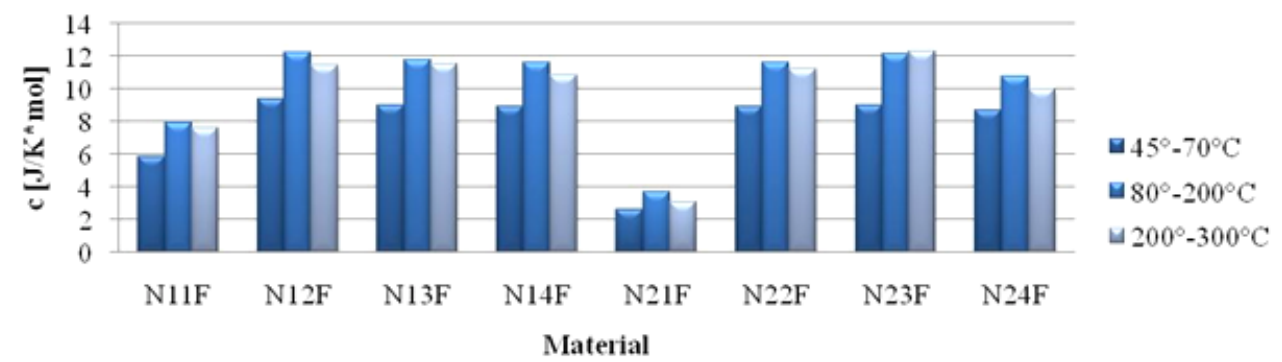

Fig. 9. Specific heat of hybrid

composites with stratified filled epoxy matrix measured on cooling curves

heat values for composite made of glass outer layers and aramid middle layers indifferent of glass fabric specific density (fig. 9). The other materials had presented an increasing of specific heat with decreasing of glass fabric specific density. Making a comparison between the nonfilled epoxy composites and stratified filled epoxy composites, it can be observed that the using of fillers in epoxy matrix led to improvement of specific heat only for composite made of carbon outer layers from materials group reinforced with lower specific density glass fabric and, also, for composite made of aramid outer layers from materials group reinforced with higher specific density glass fabric.

On $80-200^{\circ} \mathrm{C}$ and $200-300^{\circ} \mathrm{C}$ temperature ranges, the effect of replacement of the lower specific density glass fabric by one with higher specific density, it was the same as on temperature range described above, excepting the composite made of glass outer layers succeeded by carbon layers and stratified filled epoxy matrix, which show a decreasing specific heat on cooling temperature range (figs. 6 and 8). Regarding the effect of epoxy matrix modification, on $80-200^{\circ} \mathrm{C}$ temperature ranges, it was remarked that the addition of fillers mixture in epoxy matrix had improved the specific heat of the composites made of carbon outer layers and of the composites made of glass outer layers and carbon medial layers from hybrid composites group reinforced with lower specific density glass fabric (figs. 7 and 9). From hybrid composites group reinforced with higher specific density glass fabric, the specific heats of the composites made of aramid outer layers and of the composites made of glass outer layers and aramid medial layers, on both cooling temperature ranges were improved. But on heating temperature ranges the specific heat was increased only of composite with aramid outer layers. On $200-300^{\circ} \mathrm{C}$ heating temperature ranges, how it can be seen in figs. 7 and 9 , the modification of epoxy matrix improved the specific heat of all materials reinforced with lower specific density glass fabric, excepting the materials made of glass outer layers and succeeded by carbon layers. On $200-300^{\circ} \mathrm{C}$ cooling temperature ranges, it was observed an improvementonly for composite made of carbon outer layers.

\section{Conclusions}

Based on graphs above, the following conclusions over the thermal behavior of composite plates might be noticed:

All the materials showed different thermal behavior in dependence of the fabric type of outer layers, the layers configuration, the glass fabric specific density and the modification of epoxy matrix.

Regarding the effect of the fabric type of outer layers and the layers configuration, it was remarked that the composites made of aramid outer layers exhibited the lowest values of thermal expansion coefficient indifferent of the temperatures ranges, glass fabric specific density and the epoxy matrix modifying. But by increasing of glass fabric specific density, this composite showed the lowest specific heat, which has been improved by modifying of epoxy matrix and even presenting the higher specific heat on $200-300^{\circ} \mathrm{C}$ heating temperature range. Without modifying of epoxy matrix the composites made of glass fabric outer layers showed the highest values of measured specific heat.

The replacement of lower specific density glass fabric with higher specific density glass fabric in structure of composites has improved the thermal performance of composite made of glass fabric outer layers and succeeded by aramid layers. It was improved the thermal properties of composite made of carbon fabric outer layers, whose thermal expansion coefficient was reduced on 40$60^{\circ} \mathrm{C}$ temperature range and was increased significantly (approximately twice) the specific heat of this composite on all temperature ranges of measurements.

On all temperature ranges of heating and cooling curves, the modification of epoxy matrix with two types of fillers mixture had improved the specific heat of the composite made of aramid fabric outer layers from the materials group reinforced with higher specific density glass fabric. Also, it had improved significantly the specific heat of composite made of carbon fabric outer layers from the materials group reinforced with lower specific density glass fabric.

\section{References}

1. PASCAULT, J,-P., WILLIAMS, R. J . J., Epoxy Polymers. New Materials and Innovations, Wiley-VCH Verlag GmbH \& Co. KGaA, ISBN 978-3527-32480-4, 2010.

2. KRICHELDORF, H. R., NUYKEN, O., SWIFT, G., Handbook of Polymer Synthesis, Marcel Dekker, ISBN 0-8247-5473-5, 2005.

3. RENARD, J., Elaboration, microstructure et comportement des materiaux composites a matrice polymere, Lavoisier, France, ISBN 27462-0955-1, 2005.

4. REYNE, M., Technologie des composites, 2-e edition, Edition Hermes, Paris, ISBN 2-86601-455-3, 1995.

5. DEBORAH, D.L.C., Composite Materials: Science and Applications, Second Edition, Elsevier, ISBN 978-1-84882-830-8, 2010.

6.*** Advirsory Committee on Technical Recommendations for Construction, Guide for the Design and Construction of Externally Bonded FRP Systems for Strengthening Existing Structures, CNR-DT 200/2004.

7. AKOVALI, G., UYANIK, N., Handbook of Composite Fabrication, Rapra Technology Limited, ISBN 1-58957-263-4, 2001.

8. DODU, AR., PREDA, C., BUTNARU, R., VISILEANU, E., DAN, D., CÃLIN, L., GREAVU, V., GRIGORA', V., OCEANU, V., GHERMAN, ST., Manualul inginerului textilist, vol.1, Ed. AGIR, Bucuresti, ISBN 9738466-10-5, 2002.

9. CHAWLA, K. K., Fibrous Materials, Cambridge University Press, Cambridge, UK, ISBN 0-521-57079-4, 1998.

10. HEXCEL, Technical Fabrics Handbook, HexForce Reinforcements, U.S.A., FM 93570, 2010. 
11. CHRETIEN, G., Materiaux composites a matrice organique, Technique et Documentation, France, 2008.

12. MOURITZ, A.P., GIBSON, A.G., Fire Properties of Polymer Composite Materials, Springer, Netherlands, 2006.

13. CRYSTIC, Composites Handbook, Scott Bader Company Limited, 2005.

14. CIRCIUMARU, A., BRIA, V., BIRSAN, I.G., ANDREI, G., DIMA, D., Some Properties of Stratified Composites, Proceedings of the ASME $201010^{\text {th }}$ Biennial Conference on Engineering Systems Design and Analysis, Istanbul, Turkey 2010, ISBN 978-0-7918-3877-8.
15. CIRCIUMARU, A., ANDREI, G., DIMA, D., BIRSAN, I.G., BRIA, V., Thermal Properties of Some Particulate Composites, Annals of DAAAM for $2010 \&$ Proceedings of the $21^{\text {st }}$ International DAAAM Symposium, Zadar, Croatia, 2010, pp. 69-70, ISSN 1726-9679.

16. GUSTIN, J., MAHINFALAH, M., NAKHAIE JAZAR, G., AAGAAH, M.R., Low-velocity Impact of Sandwich Composite Plates, Society for Experimental Mechanics, Vol. 44, No. 6, 2004.

17. STEFANESCU, V., , BUNEA, M., CIRCIUMARU, A.,, Impact Analysis of Fabric Reinforced Plates, Mat. Plast., 52, no. 2, 2015, p. 198

Manuscript received: 23.01 .2018 